九州大学学術情報リポジトリ

Kyushu University Institutional Repository

Sexual Maturity of the Red Sea Bream Pagrus major from the Chikuzenkai, Northern Kyushu, in 1985

Lara, Ricardo Torres

CINVESTAV-IPN University

Matsuyama, Michiya

Department of Fisheries, Faculty of Agriculture, Kyushu University

Matsuura, Shuhe i

Department of Fisheries, Faculty of Agriculture, Kyushu University

https://doi.org/10.5109/23858

出版情報 : 九州大学大学院農学研究院紀要. 31 (4)，pp.383-389，1987-03-31. Kyushu University バージョン：

権利関係 : 


\title{
Sexual Maturity of the Red Sea Bream Pagrus major from the Chikuzenkai, Northern Kyushu, in 1985
}

\author{
Ricardo Torres Lara*, Michiya Matsuyama and Shuhei Matsuura \\ Department of Fisheries, Faculty of Agriculture, \\ Kyushu University 46-06, Hakozaki, Fukuoka 81'2
}

(Received December 10, 1986)

\begin{abstract}
The percentage of fish attained sexual maturity was determined by histological examination of the gonads in red sea bream, Pagrus major, in various size classes of various ages. A total of 616 fish collected in March to June, 1985, was examined. A few fish mainly at the age of 2 years were found to have bisexual gonads, but their ovarian tissue was not functional. The sex ratio of fish of the ages of 2 to 6 years was assumed to be $1: 1$ through a binomial test. Male fish attained maturity ahead of females at the beginning of the spawning season, and the ratio of mature fish increased with advancing age rapidly in males and slowly in females. The proportions of fish having mature testes of the stage IV were $0.06 \%, 79.0 \%, 96.3 \%$ and $100 \%$ at the age of 2, 3, 4 and 5 years, respectively. On the other hand, the proportions of fish having mature ovaries of the stage III or IV were $28.6 \%, 63.5 \%, 72.6 \%$, and $95.0 \%$ at the age of 2,3, 4 and 5 years, respectively.
\end{abstract}

\section{INTRODUCTION}

As the red sea bream Pagrus major is one of the most economically valuable fish as a target species of inshore and offshore fisheries and also as a major aquaculture species in Japan, research aimed at obtaining basic biological information is necessary in order to formulate the most appropriate policy for its exploitation.

From the aspect of fisheries management, studies on the reproduction of this species have been conducted since 1984 based on samplings in the Chikuzenkai region, northern Kyushu (Matsuura et al. 1987, and Matsuyama et al. 1987 a, b).

The purpose of the present study was to obtain fundamental knowledge on the reproduction of the red sea bream, i. e. the proportions of fish at different stages of sexual maturity in relation to age and size group, sex ratio and the occurrence of hermaphrodites through histological observation of the gonads.

\section{MATERIALS AND METHODS}

The red sea bream were caught by commercial fishermen using a type of seine, locally known as "Gochi-ami", and bottom trawls. Samples were taken two to four times per month during the spawning season from March 29 to June 22, 1985 (Table 1).

* CINVESTAV-IPN U. Merida, Apdo. Postal 73 Cordemex, C. P. 97310 Merida, Yucatan, Mexico 
Table 1. Sampling date and numbers of specimens of red sea bream collected from the Chikuzenkai in 1985 .

\begin{tabular}{|c|c|c|}
\hline \multicolumn{2}{|l|}{ Date } & \multirow{2}{*}{$\frac{\text { Number }}{34}$} \\
\hline March & 29 & \\
\hline April & 10 & 72 \\
\hline & 20 & 73 \\
\hline & 25 & 74 \\
\hline \multirow[t]{4}{*}{ May } & 2 & 67 \\
\hline & 10 & 51 \\
\hline & 18 & 55 \\
\hline & 23 & 83 \\
\hline \multirow[t]{2}{*}{ June } & 6 & 37 \\
\hline & 22 & 70 \\
\hline Total & & 616 \\
\hline
\end{tabular}

The ages of fish were determined by scale reading using scales taken from the pectoral fin area. Histological determinations of male and female sex cells were performed according to the criteria of Matsuura et al. (1987) and Matsuyama et al. (1987a). Since the majority of male fish caught on June 22 had testes in a spent condition, a maturity study was carried out on 240 male specimens collected from March 29 to June 6. Also, all female fish caught on March 29 were either immature or developing, and many of those caught on June 6 showed ovaries in a post-spawning condition. Accordingly, 212 female specimens collected from April 10 to May 23 were used for the histological investigation of maturity. Gonads removed from the sample fish were weighed to the nearest $0.01 \mathrm{~g}$ and preserved in $10 \%$ formalin. A segment of the central part of either of two gonadal lobes was taken for histological investigation, embedded in paraffin or celloidin, and sectioned at 5-7 $\mu \mathrm{m}$ (paraffin method) or 10-15 $\mu \mathrm{m}$ (celloidin method). The sections were stained with Mayer's haematoxylin and eosin.

\section{RESULTS}

\section{Hermaphroditism and sex ratio}

Hermaphroditic fish bearing testicular and ovarian tissues were found in the fish of ages from 2 to 3 years by histological examination. The oocytes in the bisexual gonads were at the pre-vitellogenic stage and found around the ovarian cavity. These oocytes varied in number from one individual to another. In the testicular tissue of bisexual gonads, signs of spermatogenesis were recognized. It seemed that the proportion of males decreased from the age of 5 years onwards, although the results of the binomial test did not discount the null hypothesis assuming a $1: 1$ sex ratio from the ages of 2 to 6 years. The sex composition by ages is shown in Table 2 .

\section{Maturity stages}

The degree of maturity of the gonads in the spawning season was categorized into four stages. These stages of maturity have been described by Matsuura et al. (1987) and Matsuyama et al. (1987a), as a result of research on the gonadal maturation of the 
Table 2. Numbers of female, male, and hermaphroditic red sea bream in successive age groups, with the results of the binomial test assuming a $1: 1$ sex ratio between females and males, sampled during the spawning season in 1985.

\begin{tabular}{|c|c|c|c|c|c|}
\hline \multirow{2}{*}{ A $g$ e } & \multicolumn{3}{|c|}{ Sex } & \multirow{2}{*}{ Total } & \multirow{2}{*}{$\begin{array}{c}\text { Binomial } \\
\text { test }\end{array}$} \\
\hline & Female & Male & Hermaphrodite & & \\
\hline 2 & 87 & 81 & 22 & 190 & $\mathrm{p}>0.05$ \\
\hline 3 & 82 & 80 & 2 & 165 & $\mathrm{p}>0.05$ \\
\hline 4 & 92 & 87 & 0 & 179 & $\mathrm{p}>0.05$ \\
\hline 5 & 31 & 19 & 0 & 50 & $\mathrm{p}>0.05$ \\
\hline 6 & 18 & 11 & 0 & 29 & $\mathrm{p}>0.05$ \\
\hline 7 \& over & 3 & 1 & 0 & 4 & $*$ \\
\hline
\end{tabular}

* Binomial 'test was not applied because of the small number of samples.

red sea bream. The stages of maturity were identified according to Matsuura et al. (1987) for the testis and Matsuyama et al. (1987a) for the ovary.

Maturity by age groups

The proportions of fish having mature testes of stage IV were $0.06 \%, 79.0 \%$, $96.3 \%$ and $100 \%$ at the age of 2, 3, 4 and 5 years, respectively. All fish at 5 years old or more had mature testes of stage IV. The proportions of fish having immaturedeveloping testes of stages I, II and III decreased with age (Fig. 1). With regard to the ovaries, the proportion of fish having immature ovaries of stage I was $66.1 \%$ in the 2-year-old group, but the percentage decreased with increasing age until none were found at the ages of 5 years old or more (Fig. 2). The proportion of fish having atretic ovaries of stagell increased progressively from fish of 2 years old to ones of 4 years

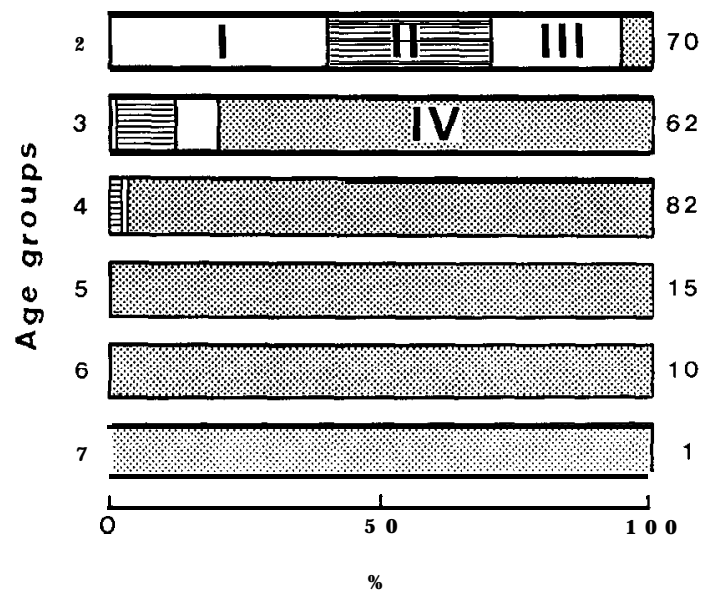

Fig. 1. Proportions of each stage of testis maturity by age of red sea bream collected during the spawning season in 1985. The numeral of the right side of each column shows the number of fish examined. 


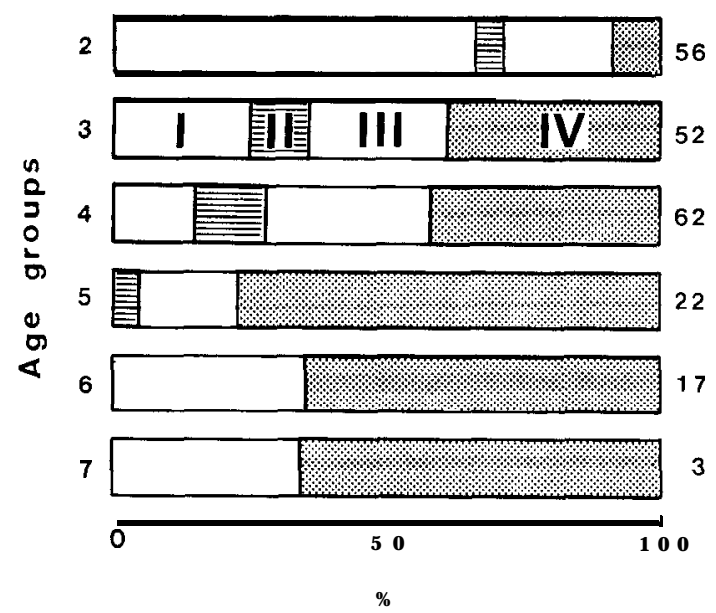

Fig. 2. Proportions of each stage of ovary maturity by age of red sea bream collected during the spawning season in 1985 . The numeral of the right side of each column shows the number of fish examined.

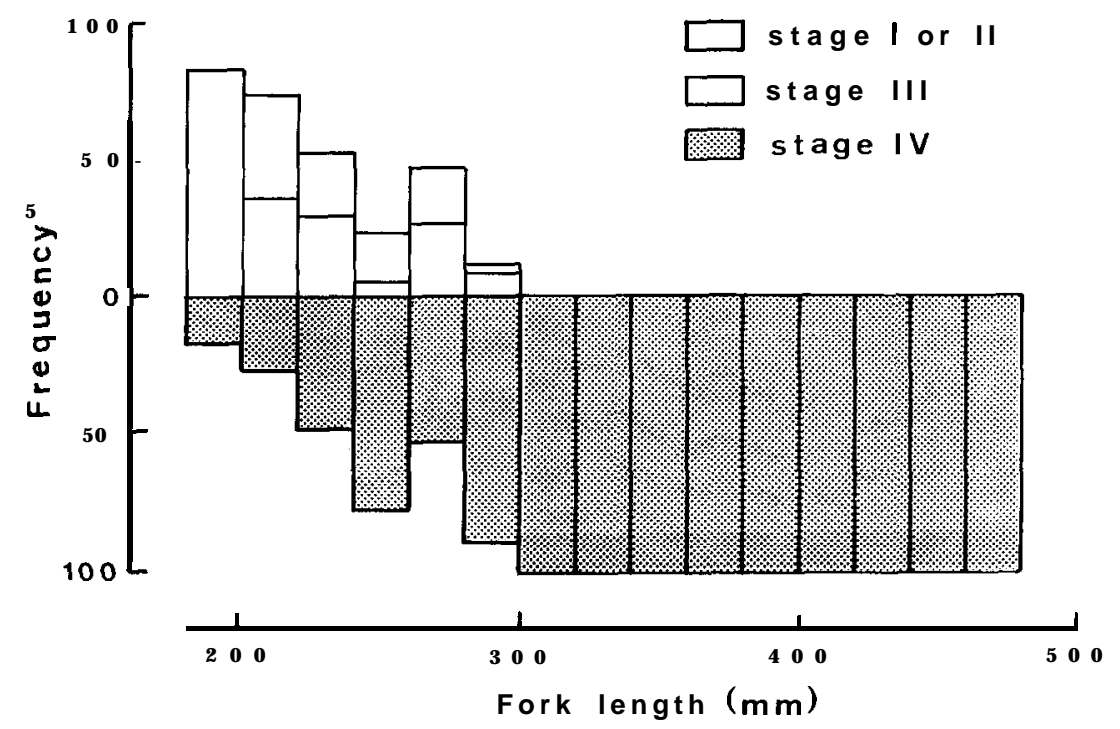

Fig. 3. Frequencies of immature (stage I or II), developing (stage III) and mature (stage IV) testes in groups of different fork length among red sea bream sampled during the spawning season in 1985.

old, decreasing quickly in 5-year-old fish and disappearing in those 6 years old or more. Fish having mature ovaries of stage IV had already appeared in 2-year-olds and their numbers increased with age thereafter. When ovaries at stage III with normally 


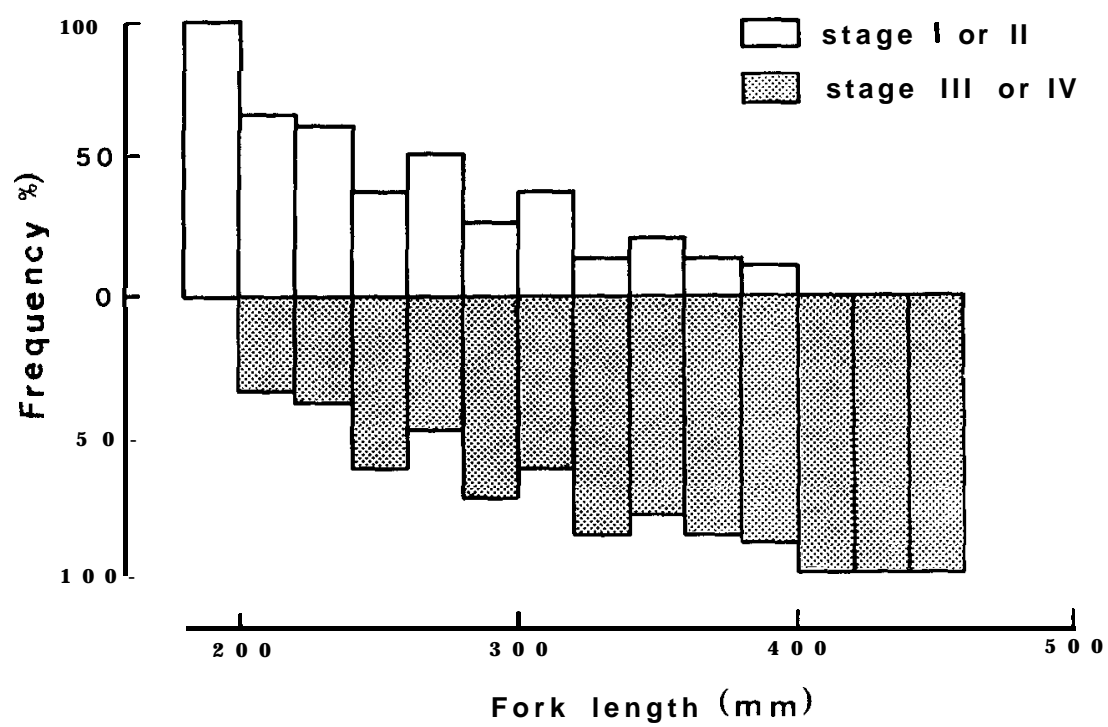

Fig. 4. Frequencies of immature (stage I or II) and mature (stage III or IV) ovaries in groups of different fork length among red sea bream sampled during the spawning season in 1985 .

developing oocytes and ovaries at stage IV were combined, under the anticipation that the ovaries at stage III were expected to attain maturity, the proportions of mature individuals at the ages of 2,3, 4 and 5 years were $28.6 \%, 63.5 \%, 72.6 \%$ and $95.0 \%$, respectively.

\section{Size at maturity}

Frequencies of each stage of gonads in different fork length groups are shown in Figs. 3 (testes) and 4 (ovaries). Mean fork length by age group for each sex is shown in Table 3. Testes at stages I and II were categorized as immature ones. Mature male fish of the stage IV initially appeared at the length group of 180-200 mm. The length

Table 3. Mean fork length by age group for each sex among red sea bream sampled during the spawning season in 1985 .

\begin{tabular}{lcccc}
\hline \multirow{2}{*}{ Age } & \multicolumn{2}{c}{ Male } & \multicolumn{2}{c}{ Female } \\
\cline { 2 - 5 } & Mean $(\mathrm{mm}) \pm \mathrm{S} . \mathrm{D}$. & $\mathrm{N}^{*}$ & Mean $(\mathrm{mm}) \pm$ S. D. & $\mathrm{N}^{*}$ \\
\hline 2 & $216.69 \pm 16.69$ & 81 & $212.05 \pm 14.27$ & 87 \\
3 & $291.96 \pm 27.55$ & 80 & $288.45 \pm 27.86$ & 82 \\
4 & $332.06 \pm 33.52$ & 87 & $328.25 \pm 40.85$ & 92 \\
5 & $359.53384 .45 \pm 37.5538 .28$ & 1911 & $376.50389 .4 \pm 44.423222$ & 3118 \\
6 & 473.00 & 1 & $418.33 \pm 18.55$ & 3 \\
\hline
\end{tabular}

\footnotetext{
* Number of specimens.
} 
at which $50 \%$ of the male fish reached maturity ranged from 220 to $240 \mathrm{~mm}$, and all fish of $300 \mathrm{~mm}$ in length and over were mature.

As for female fish, ovaries at stages III and IV were combined on the anticipation that ovaries at stage III were expected to attain maturity. No mature fish were found below a length of $200 \mathrm{~mm}$, and mature fish of stage IV initially appeared at the length group of 200-220 mm. The length at which $50 \%$ of the female fish reached maturity ranged from 240 to $280 \mathrm{~mm}$ and all fish with a length of $400 \mathrm{~mm}$ and over were mature. In both sexes, the proportions of mature individuals increased in direct correlation with the increase in length of the fish.

\section{DISCUSSION}

Histological examination of all gonads collected in the spawning season in 1985 revealed that bisexual gonads appeared in fish of the ages of 2 and 3 years, mainly at the ages of 2 years. Hermaphroditism in the red sea bream has already been discussed by Matsuyama et al. (1987b), who suggested that the phenomenon might be of a category known as "juvenile hermaphroditism". The sex ratio between females and males aged from 2 to 6 years was shown in the present study to be about 1: 1 , suggesting that the red sea bream is a gonochorist with a $1: 1$ sex ratio occurring via a hermaphroditic period in its early life.

It is interesting to note that while all the females collected on March 29 were immature or developing, the sample taken on April 10 showed a $15 \%$ proportion of mature females at stage IV. Moreover, only $21 \%$ of the males caught on March 29 were mature. However, by April 10, this percentage had increased to $82 \%$. This led us to assume that the beginning of the spawning season occurs around April 10.

The proportion of fish having mature testes of the stage IV increased dramatically from the ages of 2 to 3 during which $79 \%$ of all fish became sexually mature. The maturity rate reached $96 \%$ at the age of 4 years. It thus seems possible to accept an age of 3 years as the age at which the red sea bream attain maturity in males. This age corresponds to a mean fork length of $292.0 \mathrm{~mm}$. Since all individuals at an age of 5 or more (Fig. 1), or with a fork length of $300 \mathrm{~mm}$ or more (Fig. 3), were mature, the probability of reproductive success at this age or length seems to be very high. As mentioned previously, it was assumed that stages III and IV could be combined for mature ovaries ; the proportion of mature females increased from $29 \%$ at 2 years old to $64 \%$ at 3 years old (Fig. 2). Accordingly, an age of 3 years was accepted as the age at which the red sea bream attain maturity in females. This age corresponds to mean fork length of $288.5 \mathrm{~mm}$. Moreover, all females with a fork length of $400 \mathrm{~mm}$ or more were mature (Fig. 4). The early appearance of mature males at the beginning of the spawning season seems to be an important factor for success of reproduction in females.

It was found that the minimum length for maturity (stage IV) in males was 180$200 \mathrm{~mm}$ in 1985 and 200-220 mm in 1984 (according to Matsuura et al., 1987), and that $100 \%$ sexual maturity for all male fish was attained at the length of $300 \mathrm{~mm}$ or more in 1985 and $380 \mathrm{~mm}$ or more in 1984 (according to Matsuura et al. 1987). In the case of females, the minimum length for maturity (stages III and IV combined) was 200-220 
$\mathrm{mm}$ and the length at which $100 \%$ of the female fish attained maturity was $400 \mathrm{~mm}$ or more. These results were the same between 1984 (Matsuyama et al., 1987a) and 1985.

The duration of the spawning season was aproximately the same between 1984 and 1985, except for the slightly early appearance of ovaries with post-ovulatory signs in 1985. The above-mentioned facts suggest that the favourable environments for spawning of the red sea bream are maintained during the spawning season of April and June.

The proportions of mature fish in relation to age and size in the natural population of the red sea bream in the Chikuzenkai in 1984 and 1985 have thus been clarified. The study has supplied fundamental and common information about the reproductive biology of the red sea bream, although the information obtained was slightly different between the two years.

The reproduction process of the fish population might conceivably be affected, especially in coastal waters, by certain factors such as temperature, day length and food availability as well as population density which are related to both natural and fishing mortality. Therefore, further accumulation of detailed and fundamental information about the relationship between these factors and the age and size of maturity is desirable.

\section{ACKNOWLEDGEMENTS}

We wish to thank Professor Y. Itazawa of Kyushu University, who supported and encouraged us throughout the study, and Dr. Y. Ouchi and Mr. T. Hidaka of Fukuoka Fisheries Experiment Station of Fukuoka Prefecture, who kindly helped us in the collection of samples.

This work was partly supported by a grant from the Ministry of Education, and in part by the research fund of the Fisheries Agency, Ministry of Agriculture, Forestry and Fisheries, Japan.

\section{REFERENCES}

Matsuura, S., M. Matsuyama, Y. Ouchi and T. Hidaka 1987 Maturity classification and group maturity of the red sea bream Pagnus major: II. Maturity of male. Mar. Biol., (in press).

Matsuyama, M., S. Matsuura, Y. Ouchi and T. Hidaka 1987a Maturity classification and group maturity of the red sea bream Pagnus major: I. Maturity of female. Mar. Biol., (in press).

Matsuyama, M., R. Torres and S. Matsuura 1987b Hermaphroditism and sex ratio in the natural population of the red sea bream Pagnus major from northern Kyushu, Japan. Environ. Biol. Fishes, (submitted). 